\title{
The Effects of Temperature and Solute Diffusion on Volume Change in Sn-Bi Solder Alloys
}

\author{
QICHAO HAO ${ }^{1}$ XIN F. TAN $10,,^{1,4}$ QINFEN GU, ${ }^{2}$ KEITH SWEATMAN,${ }^{1,3}$ \\ STUART D. MCDONALD ${ }^{1}$ and KAZUHIRO NOGITA ${ }^{1}$
}

\begin{abstract}
1.-Nihon Superior Centre for the Manufacture of Electronic Materials, School of Mechanical and Mining Engineering, The University of Queensland, St. Lucia, QLD 4072, Australia. 2.-Australian Synchrotron, ANSTO, Clayton, VIC 3168, Australia. 3.-Nihon Superior Co., Ltd, Suita City, Osaka 564-0063, Japan. 4.-e-mail: xin.tan@uq.edu.au
\end{abstract}

\begin{abstract}
The different rates of thermal expansion of the many materials that make up an electronic assembly combined with temperature fluctuations are the driver of the thermal fatigue failure of solder joints. A characteristic of the $\mathrm{Sn}-\mathrm{Bi}$ system, which provided the basis for many of the low process temperature solder alloys that the electronics industry is now adopting, is the very temperature-sensitive solubility of $\mathrm{Bi}$ and $\mathrm{Sn}$ in the other phase. In this study, in situ synchrotron powder x-ray diffraction was used to characterize the temperature dependence of the lattice parameters of the $\beta \mathrm{Sn}$ and $\mathrm{Bi}$ phases in $\mathrm{Sn}-57 \mathrm{wt} \% \mathrm{Bi}$ and $\mathrm{Sn}-37 \mathrm{wt} \% \mathrm{Bi}$. The effects of temperature and solute were separated by comparing with the data from pure $\beta \mathrm{Sn}$ and pure $\mathrm{Bi}$ and verified using density functional theory calculations. Furthermore, the coefficients of thermal expansion of $\beta \mathrm{Sn}$ and $\mathrm{Bi}$ during heating were also derived to reveal the thermal expansion behavior.
\end{abstract}

\section{INTRODUCTION}

For the first 100 years of assembling components into functioning electronic circuitry, the industry depended on solder alloys based around the $\mathrm{Sn}-\mathrm{Pb}$ eutectic system to make the connections. However, due to concerns surrounding $\mathrm{Pb}$ toxicity and environmental contamination, legislation has been implemented to eliminate $\mathrm{Pb}$ from electronic assemblies. The European Union was the first to take action with its Directive on the Restriction of Hazardous Substances, ${ }^{1}$ and the Sn3.0wt\%Ag0.5wt\%Cu with the melting point of $220^{\circ} \mathrm{C}$ became a common substitute alloy for reflow soldering. ${ }^{2}$ However, due to the need to reduce energy consumption in electronics manufacturing, and the need to solder temperature-sensitive components and substrates, there is increasing interest in lead-free solder alloys that can be reflowed at a peak temperature under $200^{\circ} \mathrm{C}^{3-6}$ The solder alloys attracting the most interest are those based on the

(Received September 29, 2021; accepted December 26, 2021; published online February 2, 2022)
Sn-Bi system, which has a eutectic at about 57 wt\% $\mathrm{Bi}$ with a melting point of $139^{\circ} \mathrm{C}$, and there has been much research on the microstructure and mechanical properties of these alloys., ${ }^{3,4,7,8}$ It has been shown that the density of the eutectic Sn-Bi alloy decreases with increasing temperature, and the thermal expansion characteristics of this alloy have been characterized. ${ }^{9}$ While the thermal expansion characteristics of solder alloys are recognized as one of the factors that affect the reliability of electronic assemblies in service, ${ }^{10}$ the coefficients of thermal expansion (CTE) of eutectic Sn-Bi used in modeling is typically a single value (e.g., $15 \times 10^{-6} /{ }^{\circ} \mathrm{C}$ ) ${ }^{8}$

In service, the solder joints of electronic circuitry are exposed to temperature changes from the environment in which they operate or because of the heat generated by the functioning of the circuitry. Because electronics circuitry is made up of a large variety of materials with different CTE, any change in the temperature of the assembly from the temperature at which the solder solidified during the assembly process results in stress being applied to the solder joints that connect these different materials. ${ }^{11-13}$ The creep deformation, driven by thermally induced stress, is the driver for the thermal 
fatigue that is the most common reason for failure in electronic devices. ${ }^{14,15}$ Although not usually the major factor in the thermal fatigue process, the thermal expansion characteristics of the solder are an essential factor in the finite element modeling that is now being used increasingly in the design of electronics assemblies and in-service life prediction. ${ }^{16,17}$ However, the solid solution of $\mathrm{Bi}$ in $\mathrm{Sn}$ should not be ignored for Sn-Bi alloys, due to the fast diffusion and relatively high temperature-dependent variations. In addition, it has been proven that the presence of $\mathrm{Sn}$ as a solute in $\mathrm{Bi}$ results in shrinking of the crystal structure. ${ }^{18}$

To the best knowledge of the authors, the thermal expansion of the different phases in $\mathrm{Sn}-\mathrm{Bi}$ based solders has not been thoroughly investigated. To fill this gap, we investigated the thermal expansion behavior of the $\beta \mathrm{Sn}$ and $\mathrm{Bi}$ phases in Sn57Bi and Sn37Bi (compositions are expressed as weight percent unless otherwise specified) using powder x-ray diffraction (PXRD) carried out in the Australian Synchrotron. The results have been analyzed using density functional theory (DFT) to verify the separate effects of temperature and solute level generating data that will be useful in the interpretation of reliability testing of these solder alloys and inservice life prediction modeling.

\section{EXPERIMENTAL}

\section{Preparation of Samples}

SnxBi $(x=37 \mathrm{wt} \%, 57 \mathrm{wt} \%)$ alloys were cast from pure $\mathrm{Sn}$ and $\mathrm{Bi}$. The reason for choosing these two compositions is because the eutectic alloy $\mathrm{Sn} 57 \mathrm{Bi}$ is most widely researched due to its lowest melting point in the Sn-Bi system, and hypoeutectic Sn37Bi is an alternative option that contains significantly more of the ductile Sn phase, while still having a liquidus temperature suitable for low-temperature applications. Sn and $\mathrm{Bi}$ ingots were melted in a ceramic crucible at $450^{\circ} \mathrm{C}$ in a cantilevered box furnace for $1 \mathrm{~h}$ with frequent stirring to make the alloys homogenous, and the dross on the surface of the metal liquid was removed before casting into a preheated ingot mold. Chemical analysis of the alloys is shown in Table S-I in the Supplementary Material (refer to online supplementary material). The samples were cut using a saw, and the swarf was crushed in an agate mortar to make a fine powder to be put into a capillary for the synchrotron PXRD experiments.

\section{Microstructure Characterization}

The microstructures of Sn57Bi and Sn37Bi alloys were analyzed using scanning electron microscopy (SEM). Samples from the Sn57Bi and Sn37Bi ascast ingots were cold-mounted in epoxy resin and ground with \#320, \#600, \#1200 and \#4000 silicon carbide grinding paper, and polished to a $0.25-\mu \mathrm{m}$ finish, before being coated with a $100 \AA$ gold layer, and SEM image data were acquired using backscatter electron (BSE) mode at an accelerating voltage of $15 \mathrm{kV}$ on a Hitachi TM3030 SEM.

\section{In Situ Heating Powder x-ray Diffraction}

The in situ synchrotron powder diffraction experiments were conducted at the Powder Diffraction beamline at the Australian Synchrotron. The fine powder samples were diluted with ground quartz capillary powder to decrease the x-ray attenuation due to the high mass energy-absorbing $\mathrm{Bi}$. The mixed powder sample was placed in a quartz capillary of $500 \mu \mathrm{m}$ internal diameter and fixed on the rotary holder above the hot air blower. PXRD patterns were taken every $10^{\circ} \mathrm{C}$ from $30^{\circ} \mathrm{C}$ to $200^{\circ} \mathrm{C}$ under atmospheric pressure (Fig. 1a). The 21-keV monochromatic incident beam was calibrated by a standard $\mathrm{LaB}_{6}$ sample (NIST660b, a = 4.15689 $\mathrm{A}$, $\mathrm{Pm} \overline{3} \mathrm{~m}$ ) at room temperature, giving a wavelength of $0.5899 \AA$. The heating rate was controlled to $30^{\circ} \mathrm{C} /$ min. The diffracted x-ray pattern was recorded in transmission mode using a Mythen strip detector at two positions within $0.5^{\circ}$, and the measurement time for each position was $2 \mathrm{~min}$.

The in situ synchrotron PXRD makes it is possible to obtain the data within short timeframes, which are relevant to practical applications of solder alloys. As the time required for the alloys to reach an equilibration state at each temperature step with respect to solute diffusion can be long, ${ }^{19}$ it is desirable to know how close to equilibrium the alloys were before beginning the measurements. As such, in situ laboratory PXRD for Sn57Bi was also performed using a Rigaku Smartlab Thin Film xRay Diffractometer for comparative purposes. The system is equipped with a $9-\mathrm{kW} \mathrm{Cu}$ rotating anode and a HyPix 3000(H) detector. Undiluted powder samples were packed in a sample holder, as shown in Fig. 1b, and PXRD data were collected in BraggBrentano geometry at $30^{\circ} \mathrm{C}$ before holding at $80^{\circ} \mathrm{C}$ for $5 \mathrm{~min}$ to collect the second set of data. The sample was then held at $80^{\circ} \mathrm{C}$ for another $30 \mathrm{~min}$ before collecting the final set of data.

Due to the lack of available data in the literature, in situ laboratory PXRD for pure $\mathrm{Bi}$ was also conducted to compare the lattice parameters of the $\mathrm{Bi}$ phase in Sn-Bi alloys with pure Bi. The PXRD data were collected from $30^{\circ} \mathrm{C}$ to $250^{\circ} \mathrm{C}$ with $20^{\circ} \mathrm{C}$ intervals, as depicted in Fig. 1c.

Phase identification, the lattice parameters, and temperature-dependent $d$-spacings obtained from both synchrotron and laboratory PXRD were derived from the Rietveld refinement to the full pattern of each sample using TOPAS Academic V6 (Bruker-AXS, Germany), as shown in Fig. 3a, and the results can be found in the supplementary material. The coefficient of thermal expansion was derived by the Coefficient of Thermal Expansion Analysis Suite (CTEAS) package using a tensor method. The lattice parameters and d-spacings for 
(a)

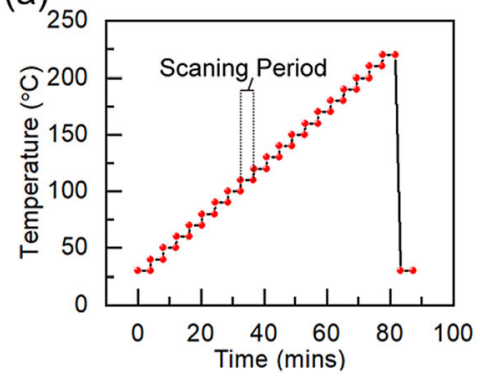

(b)

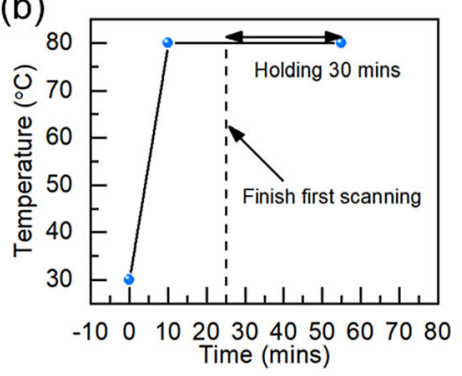

(c)

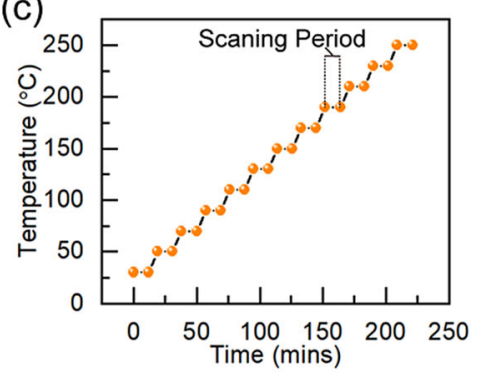

Fig. 1. Temperature profiles of (a) in situ synchrotron PXRD for Sn-Bi alloy samples, (b) laboratory PXRD for Sn57Bi, and (c) laboratory PXRD for $\mathrm{Bi}$

each temperature obtained from the Rietveld refinement could be used as inputs for the CTEAS, and then a thermal expansion tensor could be calculated based on the crystal structure, which enables the CTEAS to calculate the three-dimensional thermal expansion.

\section{Density Functional Theory (DFT) Calculations}

The first-principle calculation for the optimization of crystal structure was performed using the Vienna ab initio software package (VASP, v.5.4.4) assisted by VESTA. ${ }^{20}$ The exchange-correlation functional for the calculation was based consistently on the generalized gradient approximations, as parameterized in the Perdew-Burke-Ernzerhof functional, and the projector augmented wave method was used for the calculations. The valence electrons for $\mathrm{Sn}$ and $\mathrm{Bi}$ were $5 s^{2} 5 p^{2}$ and $6 s^{2} 6 p^{3}$, respectively. To simulate the diffusion of $\mathrm{Bi}$ in $\mathrm{Sn}$, a $2 \times 2 \times 2$ supercell (Sn32) of $\beta \mathrm{Sn}$ (unit cell space group I41/ amd, $\mathrm{a}=11.6634 \AA, \mathrm{c}=6.3636 \AA$ ) was prepared, and models for the replacement of one atom and two atoms of $\mathrm{Sn}$ by Bi were established corresponding to 3.125 at.\% and 6.25 at.\% solution concentrations of $\mathrm{Bi}$ in $\mathrm{Sn}$, which correspond to maximum equilibrium solubilities of around $60^{\circ} \mathrm{C}$ and $93^{\circ} \mathrm{C}$, respectively. ${ }^{21}$ The integration of the Brillouin zone was performed using the Monkhorst-Pack grid, and the KPOINTS mesh was set as $x \times x \times(x+2)$ to examine the convergence of total energy $\left(E_{\text {tot }}\right)$. The KPOINTS over $3 \times 3 \times 5$ and the cut-off energy of $500 \mathrm{eV}$ were used in all the calculations to ensure the $E_{\text {tot }}$ could converge within $1 \mathrm{meV} /$ atom.

\section{RESULTS AND DISCUSSION}

\section{Microstructure}

The SEM images in Fig. 2 show the microstructure of the Sn57Bi and Sn37Bi, in which the dark areas are $\beta \mathrm{Sn}$, the light areas are $\mathrm{Bi}$, and the areas of an intermediate shade of gray (Fig. 2c) are Bi that has precipitated on the surface of the samples. The Sn57Bi alloy has the lamella structure of alternating layers of $\beta \mathrm{Sn}$ and $\mathrm{Bi}$ characteristic of the coupled growth of a eutectic. In the hypoeutectic Sn37Bi, the eutectic phase occupies the spaces between the primary $\beta$ Sn dendrites. As the solid solubility of $\mathrm{Bi}$ in $\beta \mathrm{Sn}$ decreases with decreasing temperature, it precipitates out of solution. In the primary $\beta \mathrm{Sn}$ dendrites of the $\mathrm{Sn} 37 \mathrm{Bi}$, the $\mathrm{Bi}$ precipitates within the $\beta \mathrm{Sn}$ phase, and in Fig. 2 can be seen as fine spherical and rod-shaped particles. However, in the Sn57Bi, because the diffusion distance is short, the $\mathrm{Bi}$ can precipitate at the interface, with the eutectic $\mathrm{Bi}$ phase coarsening the eutectic Bi lamellae. The microstructure is also affected by the cooling rate after solidification is complete. At a slower cooling rate, there would be more time for the $\mathrm{Bi}$ to precipitate, so that there would be more $\mathrm{Bi}$ in the $\beta \mathrm{Sn}^{22}$

\section{Thermal Expansion Behavior of $\boldsymbol{\beta}$ Sn}

\section{Lattice Parameters of $\beta$ Sn}

Based on the comparison of the results from in situ laboratory PXRD and synchrotron PXRD data for $\mathrm{Sn} 57 \mathrm{Bi}$, it was verified that the longer time used in the laboratory PXRD does not significantly affect the lattice parameters for a given temperature. This means that the diffusion of $\mathrm{Bi}$ in $\mathrm{Sn}$ is relatively fast in the first few minutes, so that the time intervals used for measurements in the synchrotron PXRD experiments were sufficient to ensure that the microstructure had stabilized to the same extent as was achieved in the 5-90 min used in the laboratory PXRD (details are presented in the supplementary material). It can be seen from Fig. $3 \mathrm{c}$ and $\mathrm{d}$ that the lattice parameters of $\beta \mathrm{Sn}$ in $\mathrm{Sn}-\mathrm{Bi}$ alloys are larger than those of pure $\beta \mathrm{Sn}$ throughout the temperature profile, and, in the presence of $\mathrm{Bi}$ there is a non-linear increase in these lattice parameters during the heating process below the eutectic temperature, which is in contrast to the nearly linear increase in the lattice parameters of pure $\beta$ Sn with increasing temperature. ${ }^{23}$ Similarly, the lattice parameters of $\mathrm{Sn}$ in $\mathrm{Sn}-0.7 \mathrm{Cu}$ and $\mathrm{Sn}-$ $0.7 \mathrm{Cu}-1.5 \mathrm{Bi}$ also increase linearly with temperature. ${ }^{24}$ After increasing the temperature beyond the eutectic temperature, the lattice parameters decrease as the temperature rises for the Sn37Bi 

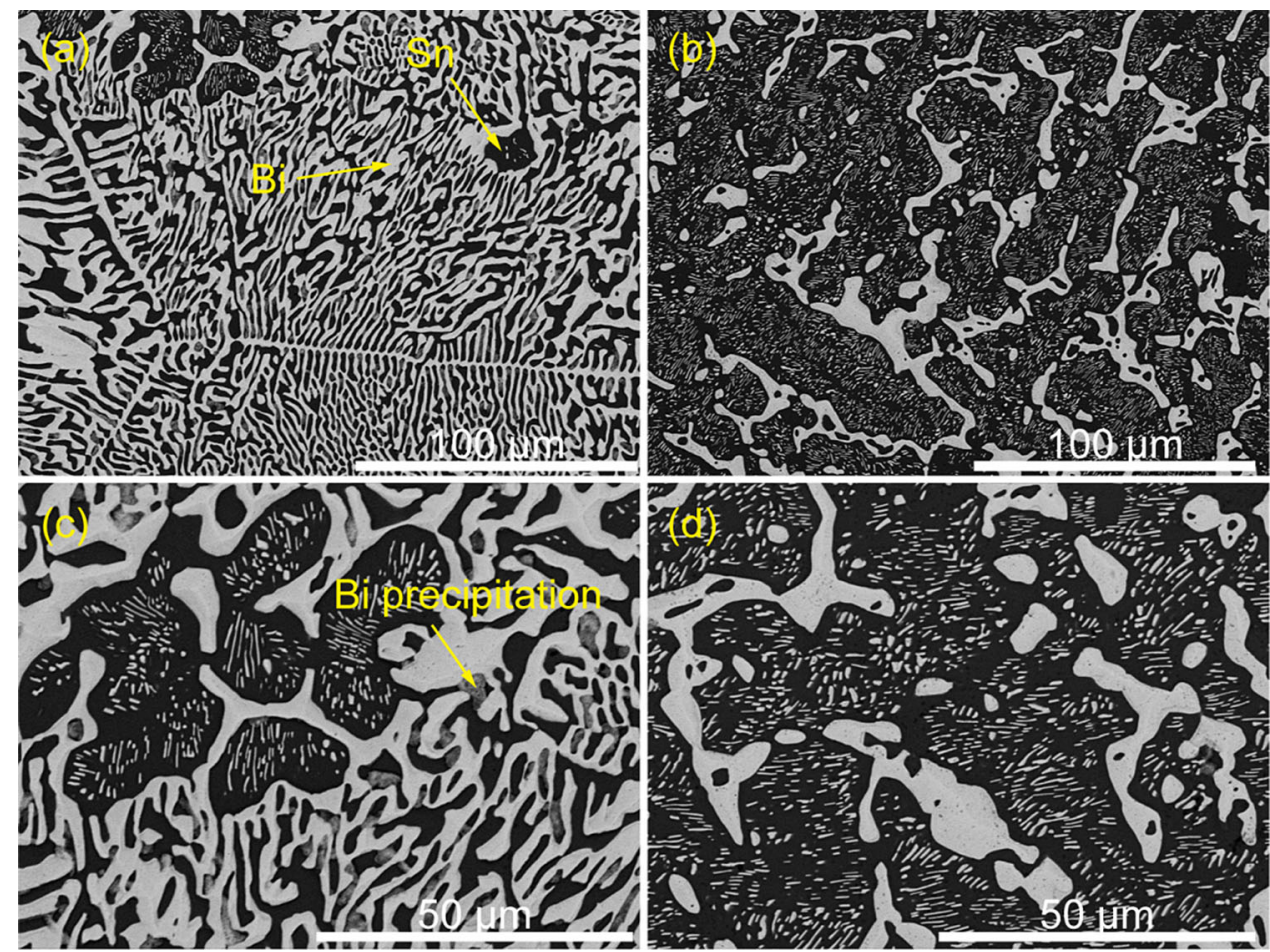

Fig. 2. SEM-BSE images of (a) and (c) Sn57Bi, (b) and (d) Sn37Bi.

alloy (it is noted that the Sn phase in the Sn57Bi alloy melts above the eutectic temperature).

The results indicate that expansion of the lattice due to temperature alone is not the only factor causing the change of the crystal structure. Indeed, it is clear that the lattice parameters follow a trend that can be rationally interpreted with respect to the shape of the solvus in the Sn-Bi equilibrium phase diagram shown in Fig. 3b. At temperatures below the eutectic temperature, as the temperature increases, the concentration of $\mathrm{Bi}$ that can be dissolved into $\mathrm{Sn}$ is increasing, and the lattice parameters increase in magnitude during heating, beyond what is expected from the literature data on pure $\beta \mathrm{Sn}$. This is expected as $\mathrm{Bi}$ atoms (atomic radius $=160 \mathrm{pm}^{25}$ ) are larger than $\mathrm{Sn}$ atoms (atomic radius $=145 \mathrm{pm}^{25}$ ), and the $\mathrm{Bi}$ is likely to substitute Sn atoms resulting in the lattice expansion. Similarly, after the eutectic temperature is exceeded (in the $\mathrm{Sn} 37 \mathrm{Bi}$ ), there is a decrease in the amount of $\mathrm{Bi}$ that can be dissolved into Sn and an accompanying decrease in the lattice parameters as the temperature increases, as shown in Fig. 3c, $d$ and e. Therefore, it is reasonable that the lattice parameters in Sn-Bi alloys are influenced by both the temperature and the concentration of $\mathrm{Bi}$ in the alloy. Figure $3 \mathrm{f}$ shows the lattice parameter ratio of $c / a$ in $\mathrm{Sn}-\mathrm{Bi}$ alloys and pure $\beta \mathrm{Sn}$, from which it is clear that this has a complex behavior with an initial increase with temperature followed by a decrease from around $70^{\circ} \mathrm{C}$. This might be because, when the concentration of $\mathrm{Bi}$ in $\beta \mathrm{Sn}$ is low, the distribution is nearly homogeneous, and the lattice parameter in the $c$ direction is smaller than that in the $a$ direction, thus a change of the same magnitude will result in a larger ratio. However, as the $\mathrm{Bi}$ concentration increases, the Bi-rich layers tend to form parallel to the (001) planes, as lower energy results from $\mathrm{Bi}$ atoms staying as far away as possible, so that they do not distribute homogeneously in the shorter $c$ direction, which will cause a larger expansion in the $a$-axis compared to the caxis.

\section{Directional CTE Determination of $\beta$ Sn}

Based on the temperature-dependent d-spacings derived from the refinement of the diffraction patterns, the directional CTE of $\beta \mathrm{Sn}$ in $\mathrm{Sn} 57 \mathrm{Bi}$ and Sn37Bi were analyzed using a tensor method. ${ }^{26,27}$ According to the results of Sn57Bi shown in Fig. 4, the CTE along the $a$ direction at low temperature is lower than the CTE in the $c$ direction. However, the CTE along the $a$ direction increases faster, and Fig. 4b showing the CTE in the $a, b$, and $c$ directions versus temperature indicates the CTE along the $a$ direction surpasses the CTE in the $c$ direction at around $70^{\circ} \mathrm{C}$, which is also evident in the pattern of the $c / a$ ratio in Fig. 3f. Figure $4 \mathrm{c}$ and $\mathrm{d}$ shows that the CTE of the $\beta \mathrm{Sn}$ phase is anisotropic at low temperature and becomes more isotropic as the temperature increases. This behaves differently from the anisotropic CTE of pure $\beta \mathrm{Sn}$ at high temperature, ${ }^{28}$ which might also be the result of diffusion of $\mathrm{Bi}$ into $\beta \mathrm{Sn}$ influencing the $a$ direction more than $c$ 

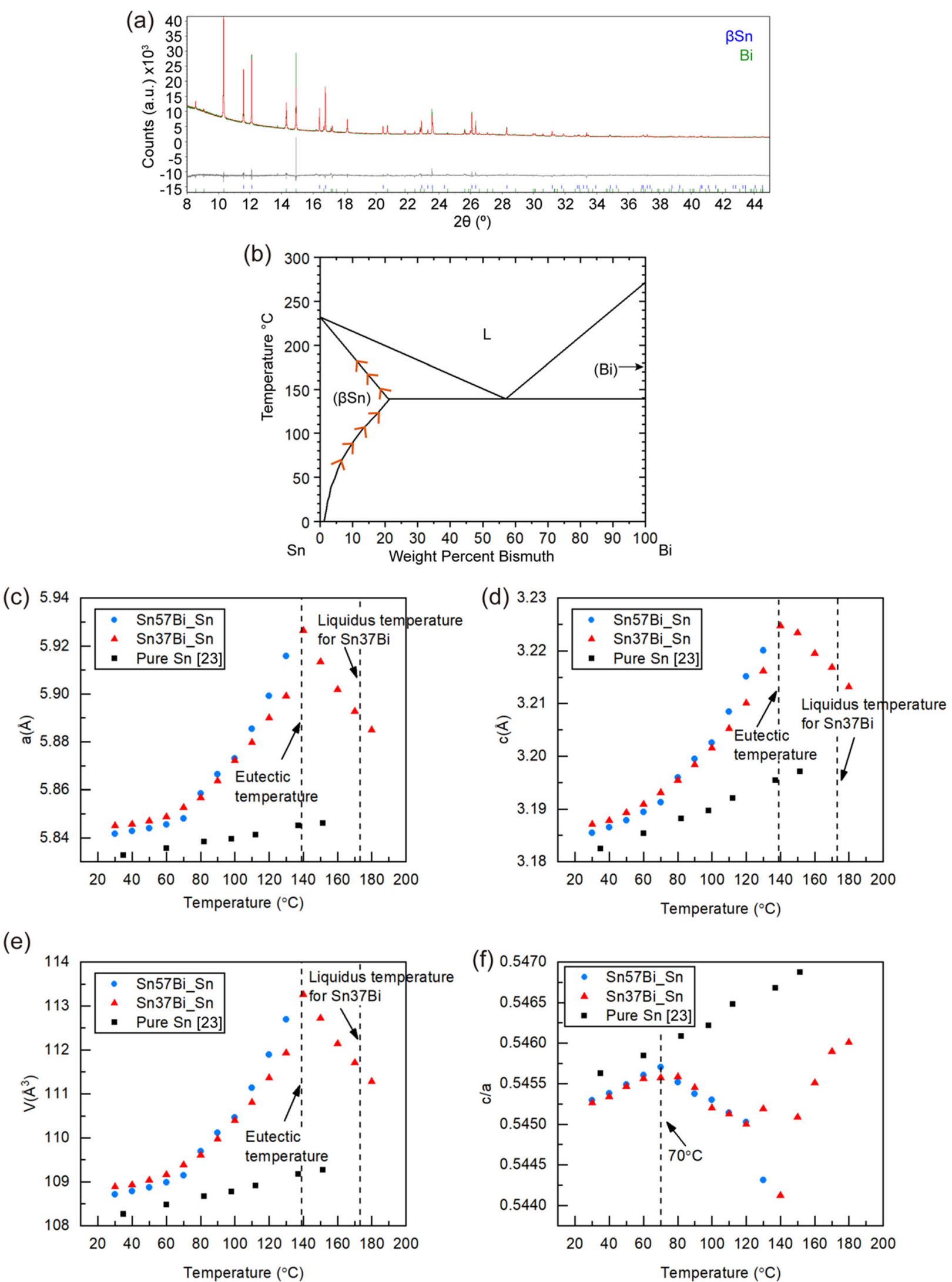

Fig. 3. (a) Rietveld refinement of the synchrotron PXRD pattern for $\mathrm{Sn} 37 \mathrm{Bi}$ at $30^{\circ} \mathrm{C}$, (b) phase diagram for binary $\mathrm{Sn}-\mathrm{Bi},{ }^{21}$ lattice parameters of $\beta \mathrm{Sn}$ in $\mathrm{Sn} 57 \mathrm{Bi}, \mathrm{Sn} 37 \mathrm{Bi}$ and lattice parameters for pure $\beta \mathrm{Sn},{ }^{23}$ (c) cell size, $a$, (d) cell size, $c$, (e) cell volume, $V$, (f) $c / a$ ratio 
(a)

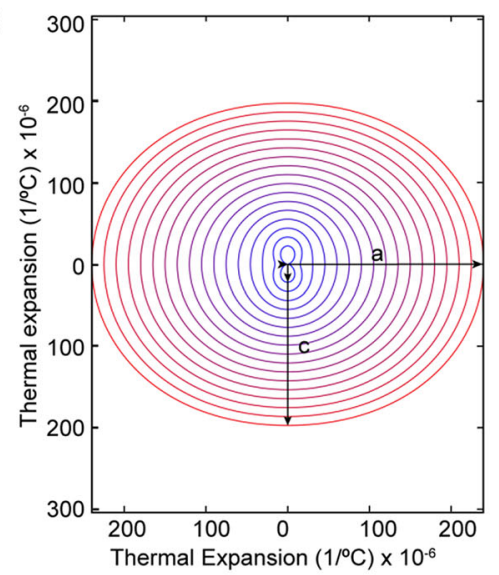

(c)

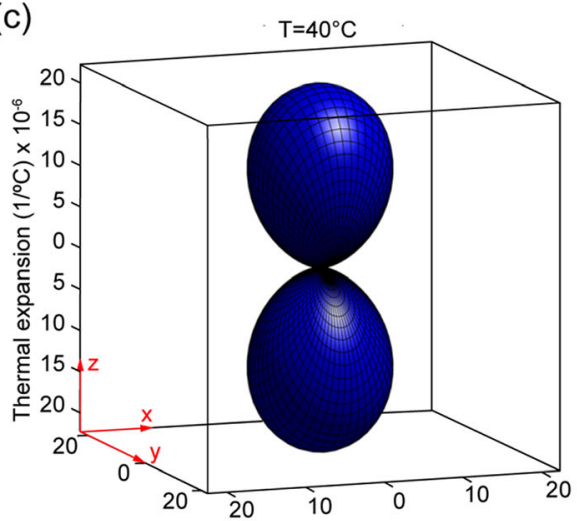

(b)

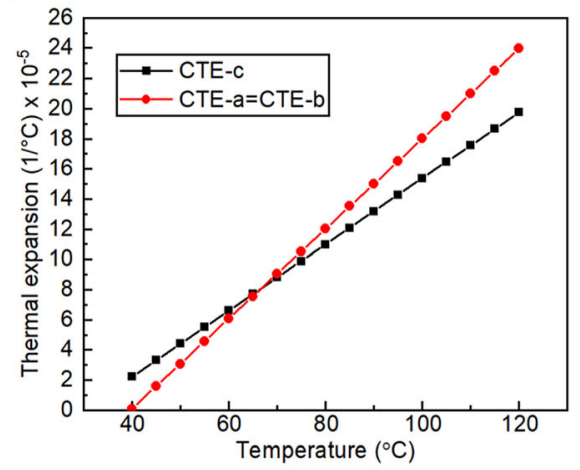

(d)

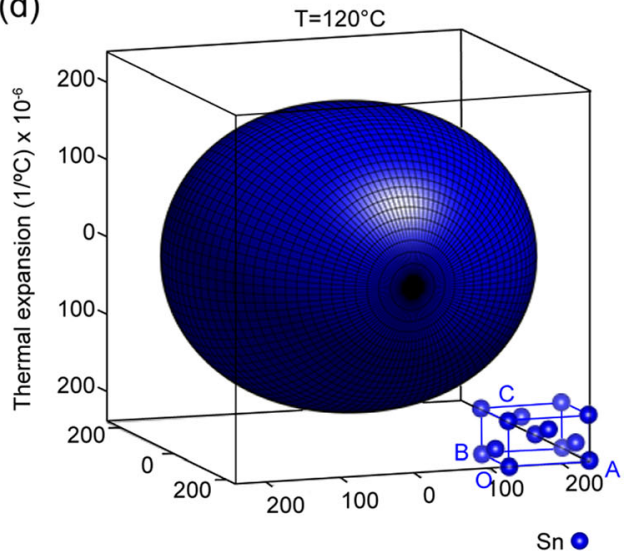

Fig. 4. CTE for $\beta \mathrm{Sn}$ in Sn57Bi alloys (a) Sn (010) CTE eigenvectors showing expansion from $40^{\circ} \mathrm{C}$ to $120^{\circ} \mathrm{C}$ calculated by the tensor method, (b) Sn CTE in the $a, b$, and $c$ direction versus temperature, (c) Sn CTE ellipsoid at $40^{\circ} \mathrm{C}$ in the Cartesian coordinate system, and (d) Sn CTE ellipsoid at $120^{\circ} \mathrm{C}$ in the Cartesian coordinate system relative to the tetragonal unit cell (blue wireframe)

direction when the concentration of $\mathrm{Bi}$ is high. The CTE of Sn37Bi showed a similar trend to that of Sn57Bi.

\section{Crystal Structure Variation Calculated by Density Functional Theory}

The models prepared for DFT calculations are shown in Fig. 5a-f. For the model involving one replacement $\mathrm{Bi}$ atom, the position for replacement does not matter due to the universal symmetry of the crystal structure. For the model involving two $\mathrm{Bi}$ atoms, the models in Fig. $5 \mathrm{c}, \mathrm{d}$, e and $\mathrm{f}$ were chosen for the experiments because the positions in these four structures show high symmetry, and the distance between the two $\mathrm{Bi}$ atoms is larger than in other situations, which could help balance the interaction energy between the atomic nuclei and minimize the total free energy.

The convergence of KPOINTS was tested using the one $\mathrm{Bi}$ atom replacement model (Fig. 5b). The total free energy $\left(E_{(\text {tot })}\right)$ changed little when the KPOINTS mesh was $2 \times 2 \times 4$ or larger (details can be found in the supplementary material). Therefore, the mesh points chosen for DFT calculation for the experiments were $3 \times 3 \times 5$.
The optimization of the crystal structure using DFT shows that, if the model of Fig. 5c or (e) was adopted, the crystal structure would change to the orthorhombic structure, which does not coincide with the PXRD results. For the models (d) and (f), the formation enthalpy $(\Delta \mathrm{H})$ equation is used to evaluate the stability of these two structures:

$$
\begin{gathered}
\Delta H=\frac{1}{32}\left\{E_{S n(32-x) \operatorname{Bi}(x)}+x E_{S n}\right. \\
\left.-\left[E_{S n 32}+x E_{B i}\right]\right\}
\end{gathered}
$$

where $E_{S n(32-x) \operatorname{Bi}(x)}$ and $E_{S n 32}$ are the total energy of the $2 \times 2 \times 2$ supercells corresponding to $\beta \mathrm{Sn}$ with and without $\mathrm{Bi}$, respectively, and $E_{S n}$ and $E_{B i}$ are the total energy per atom of each constituent element in its pure crystal state, respectively.

The formation enthalpy of model (d) is derived as $0.01549 \mathrm{eV} /$ atom, which is slightly lower than model $\mathrm{f}(0.01551 \mathrm{eV} /$ atom $)$, therefore model $(\mathrm{d})$ is chosen for the crystal structure prediction in the DFT calculation. This also supports the hypothesis that the Birich plane tends to form parallel to the (001) plane. The calculated unit cell volume for different concentrations of $\mathrm{Bi}$ is shown in Fig. 5g. The volume of the unit cell increases while the concentration of $\mathrm{Bi}$ 

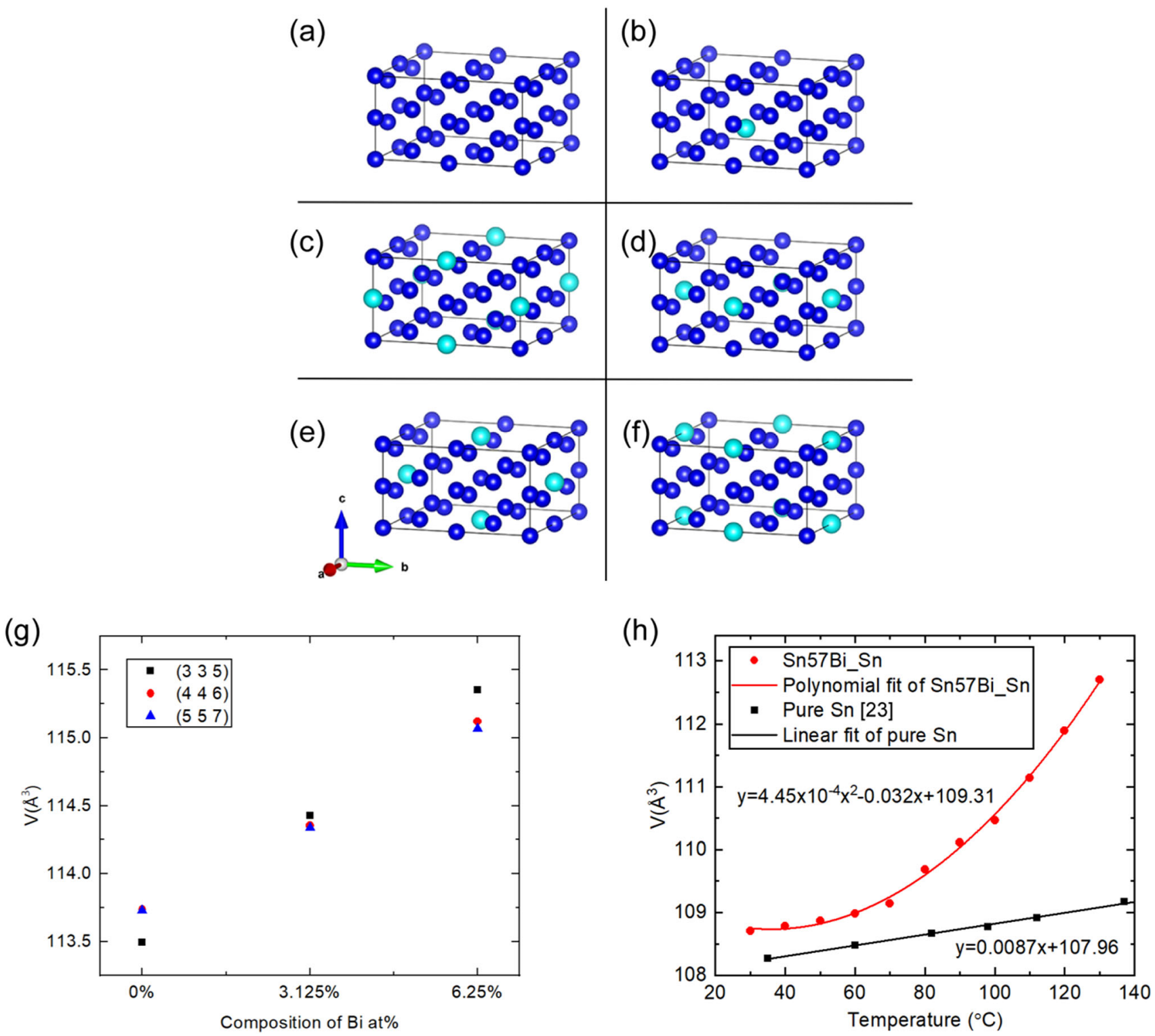

Fig. 5. Supercells models: (a) $2 \times 2 \times 2$ supercell of $\beta S n$, (b) one $\mathrm{Sn}$ atom was replaced by one Bi atom, (c-f) four different replacement positions for incorporating two $\mathrm{Bi}$ atoms in the supercell, $(\mathrm{g})$ unit cell volume derived from different mesh versus concentrations of $\mathrm{Bi}$ derived from DFT calculations with different KPOINTS meshes, and (h) unit cell volume for pure $\mathrm{Sn}$ from the literature, ${ }^{23}$ and unit cell volume for $\mathrm{Sn57Bi}$ from the PXRD measurements

rises, which agrees with the results of the PXRD data.

The change of unit cell volume versus temperature for pure $\beta \mathrm{Sn}$ was derived from the lattice parameter data in the literature, and it shows a linear relationship between volume and temperature, as shown in Fig. $5 \mathrm{~h} .{ }^{23}$ The volume increase of the $\beta \mathrm{Sn}$ phase expected by a change in temperature alone can be calculated based on the equation of best fit shown in this figure, which is $0.26 \%$. Similarly, we can get the unit cell volume at $60^{\circ} \mathrm{C}$ and $93^{\circ} \mathrm{C}$ for $\beta \mathrm{Sn}$ in the Sn57Bi from the in situ synchrotron PXRD data (Fig. 5h) and calculate the volume change across these two temperatures, which is
$1.09 \%$. The unit volume change expected from a change in solubility is estimated from the DFT calculation results as $0.81 \%$.

To analyze how the combination of solute concentration and temperature impact thermal expansion, assumptions could be made as below:

1. Temperature has a direct effect on expansion and an indirect effect through changing the solubility limits and subsequent diffusion.

2. The total impact is assumed as the multiplication of the effect of temperature and diffusion.

Thus, the total volume change caused by temperature and diffusion could be calculated using: 


$$
c_{t o t}=\left(1+c_{T}\right) \times\left(1+c_{D}\right)-1
$$

where $c_{t o t}$ is percentage of the total volume change of the unit cell, $c_{T}$ is percentage of the volume change caused by temperature, and $c_{D}$ is percentage of the volume change caused by diffusion.

Substituting the data derived into Eq. 2, the $c_{t o t}$ is calculated as $1.08 \%$, which is close to the experimental result of $1.09 \%$. The calculated results also indicate that the change due to the variation of maximum solubility and diffusion of $\mathrm{Bi}$ is more significant compared to that caused by temperature, which is consistent with the synchrotron PXRD results shown in Fig. 3. The results of the DFT apply to the assumption of equilibrium and, as per the discussion above, this would take a significant time to be achieved; ${ }^{19}$ nevertheless, the results of the DFT calculations provide a detailed insight into the diffusion effects of $\mathrm{Bi}$ in $\mathrm{Sn}$ and the change of the crystal structure.

\section{Thermal Expansion Behavior of Bi}

\section{Detectable Bi During Heating up}

Changes in the Bi phase in the Sn-Bi alloys were also investigated. Figure 6. shows the PXRD patterns for Sn37Bi and Sn57Bi at different temperatures. From the phase diagram in Fig. $3 \mathrm{~b}$, the eutectic point is around $139^{\circ} \mathrm{C} .{ }^{4,8}$ Therefore, if the temperature is higher than this eutectic temperature, the eutectic phases in the alloys should not be present and a homogeneous liquid should be present. Therefore, in the Sn-rich hypoeutectic alloy, only the primary Sn phase is expected to remain as a solid and the Bi phase should not be detected in the PXRD pattern. However, Fig. 6 indicates that the $\mathrm{Bi}$ phase is detectable after the eutectic point, and, although the signal of $\mathrm{Bi}$ decreases significantly around the eutectic point, it is still strong in the Sn-37Bi alloys. Furthermore, for both Sn37Bi and $\mathrm{Sn} 57 \mathrm{Bi}$, whose melting points are around $172^{\circ} \mathrm{C}$ and $139^{\circ} \mathrm{C}$, respectively, the $\mathrm{Bi}$ phase is still detectable after the alloys fully melt. (a)

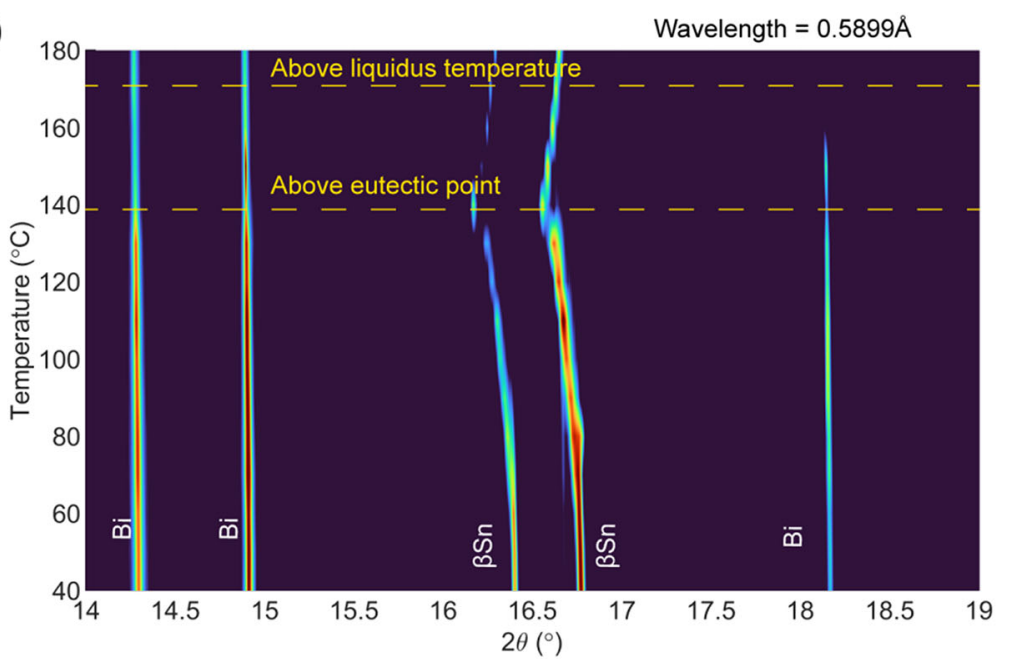

(b)

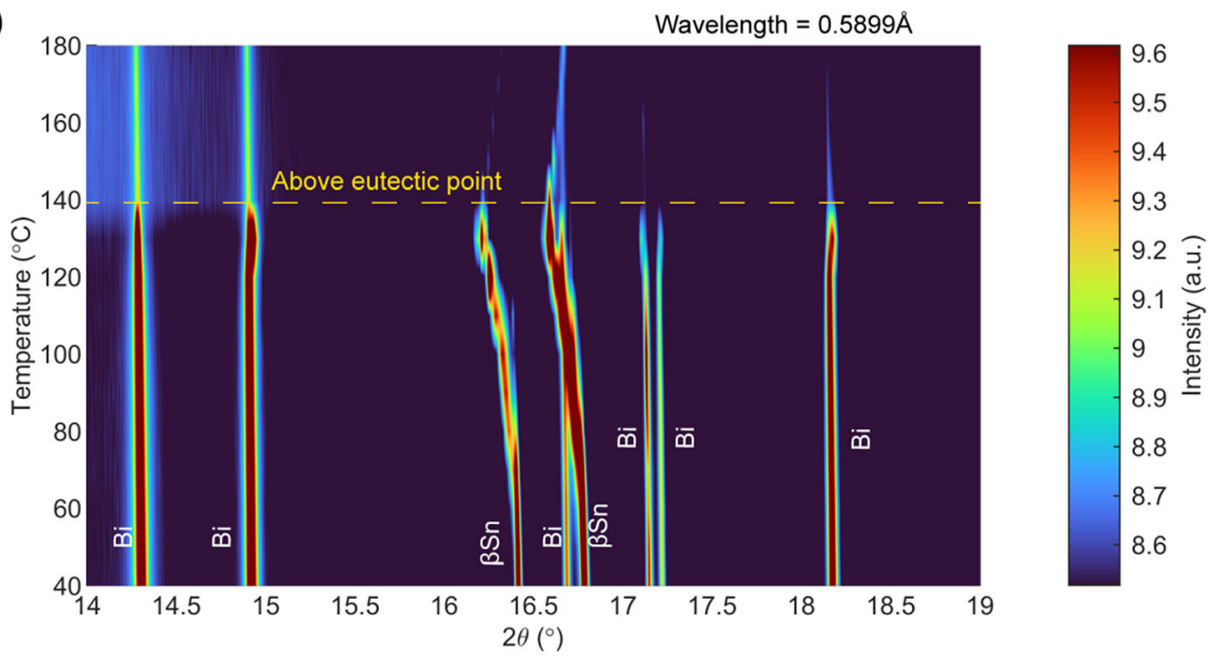

Fig. 6. PXRD patterns of (a) Sn37Bi and (b) Sn57Bi 
The Bi signals indicate that the Bi exists as a solid even above the liquidus temperature in the $\mathrm{Sn}-\mathrm{Bi}$ alloys. It seems that some residual $\mathrm{Bi}$ particles do not melt during the whole heating process. We can also see much $\mathrm{Bi}$ segregation within the primary $\beta$ Sn phase in Fig. $2 \mathrm{a}$ and $\mathrm{b}$. This unmelted Bi might be a major contributor to the signal detected after the eutectic point, and, on the basis of the discussion in Sect. 3.2, the Bi will precipitate from the $\mathrm{Sn}$ phase after the eutectic point, which might also contribute to the intensity of the Bi peaks.

\section{Lattice Parameters of $\mathrm{Bi}$}

The lattice parameters of the Bi phase in $\mathrm{Sn} 57 \mathrm{Bi}$, $\mathrm{Sn} 37 \mathrm{Bi}$, and pure $\mathrm{Bi}$ versus temperature derived from the PXRD patterns are shown in Fig. 7. For the Bi phase, the lattice parameters of $a$ in Sn-Bi alloys shown in Fig. 7 a are lower than that in pure $\mathrm{Bi}$, and the lattice parameter $c$ in Fig. $7 \mathrm{~b}$ is similar. The total volume of the unit cell of $\mathrm{Bi}$ phase in $\mathrm{Sn} 57 \mathrm{Bi}$ and $\mathrm{Sn} 37 \mathrm{Bi}$ is lower than that of pure $\mathrm{Bi}$. As the temperature increases, the lattice parameters show an increasing trend. It is noticed that in the Sn37Bi alloy there is an inflection in the graph in the vicinity of the eutectic temperature at $140^{\circ} \mathrm{C}$.
Furthermore, compared with the pure $\mathrm{Bi}$, the ratio of $c / a$ in $\mathrm{Sn} 57 \mathrm{Bi}$ and $\mathrm{Sn} 37 \mathrm{Bi}$ is more stable.

The data in Fig. 7 show that the change of lattice parameters of $\mathrm{Bi}$ depends mainly on the temperature. However, the lower parameters of $a$ and unit volume in the pure $\mathrm{Bi}$ also indicate that the diffusion of $\mathrm{Sn}$ in $\mathrm{Bi}$ has a notable effect, even though the Bi-rich phase is nearly pure, and the maximum solubility of $\mathrm{Sn}$ in $\mathrm{Bi}$ is reportedly low. ${ }^{29,30}$ The inflection in the lattice parameter data for $\mathrm{Sn} 37 \mathrm{Bi}$ before and after the eutectic point may indicate an effect associated with changing solubility of $\mathrm{Sn}$ in the Bi phase. It could be predicted from the results above that the presence of $\mathrm{Sn}$ atoms in the $\mathrm{Bi}$ phase results in a contraction of the unit cell. If this change of crystal structure is caused by interstitial atoms, the unit volume should increase, which does not align with the results. Thus, it is likely that the substitution of the $\mathrm{Bi}$ atoms by $\mathrm{Sn}$ atoms in the crystal structure leads to a shrinking of the unit cell. The inflection near the eutectic point may be associated with $\mathrm{Sn}$ precipitating from the $\mathrm{Bi}$ phase as the temperature continually increases, and the unit cell may expand due to both the releasing of Sn atoms and the increased temperature. Due to this phenomenon, the increase with temperature of
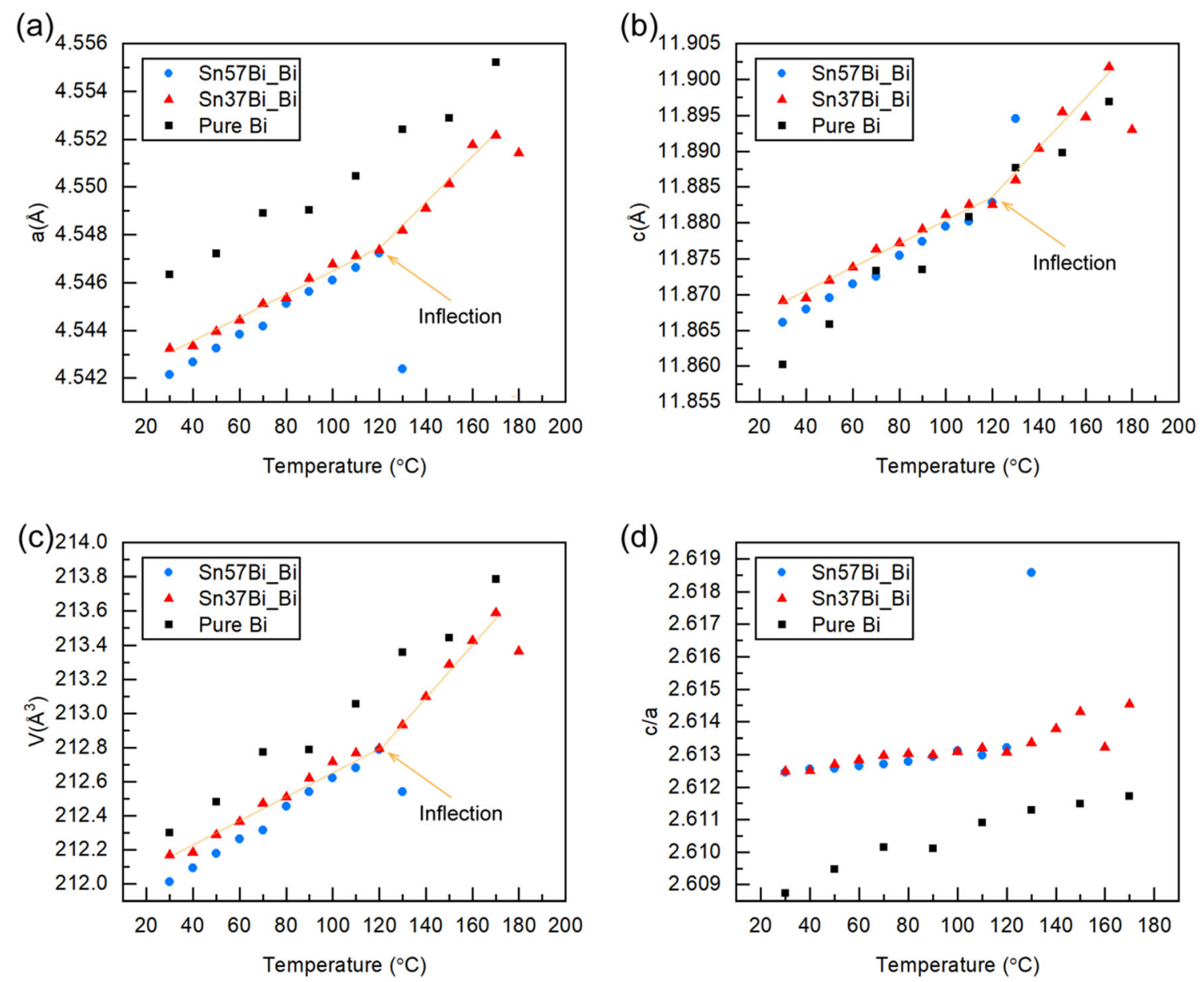

Fig. 7. Lattice parameters of $\mathrm{Bi}$ in $\mathrm{Sn} 57 \mathrm{Bi}$ and $\mathrm{Sn} 37 \mathrm{Bi}$, and lattice parameters for pure $\mathrm{Bi}$ (a) cell size, $a$, (b) cell size, $c$, (c) cell volume, $V$, and (d) cla ratio 
(a)

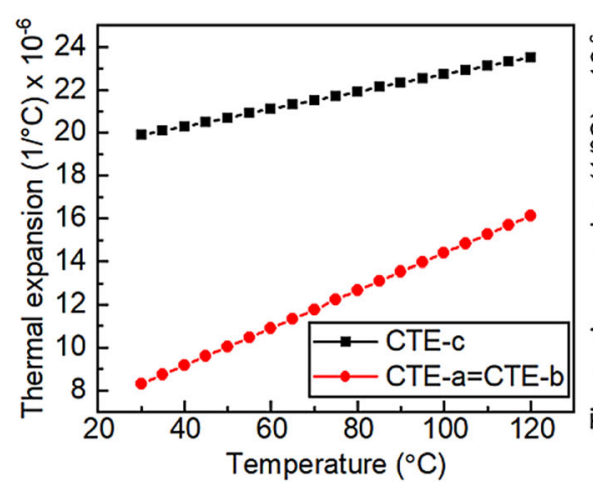

(b)

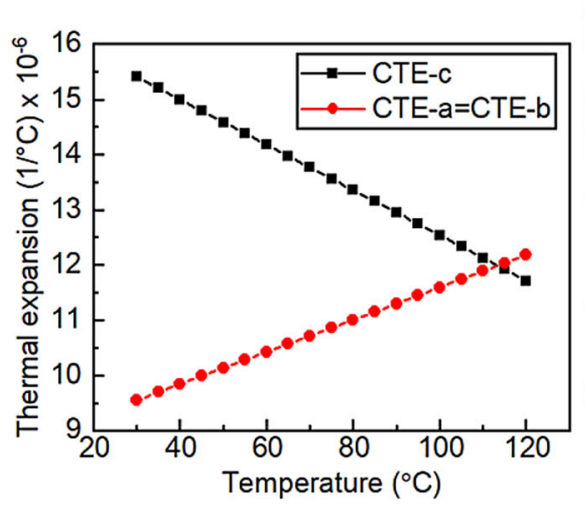

(c)

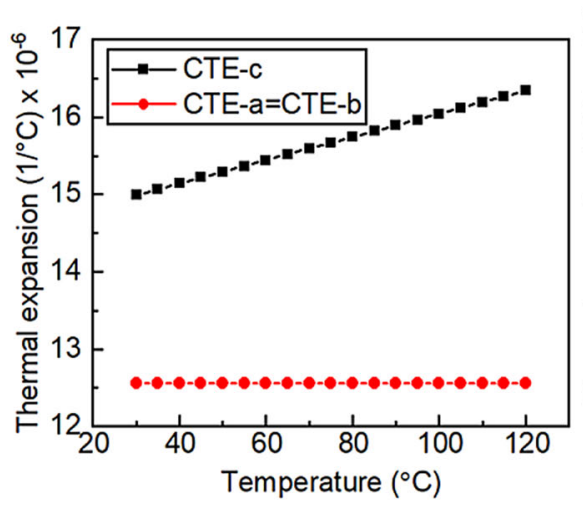

(d)

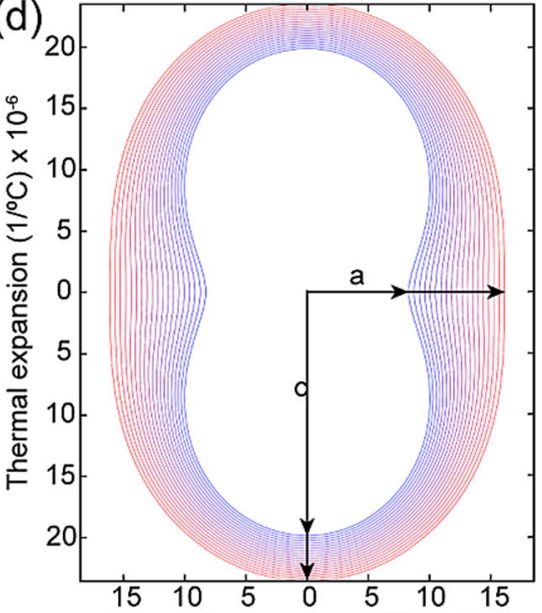

(e) Thermal expansion $\left(1 /^{\circ} \mathrm{C}\right) \times 10^{-6}$

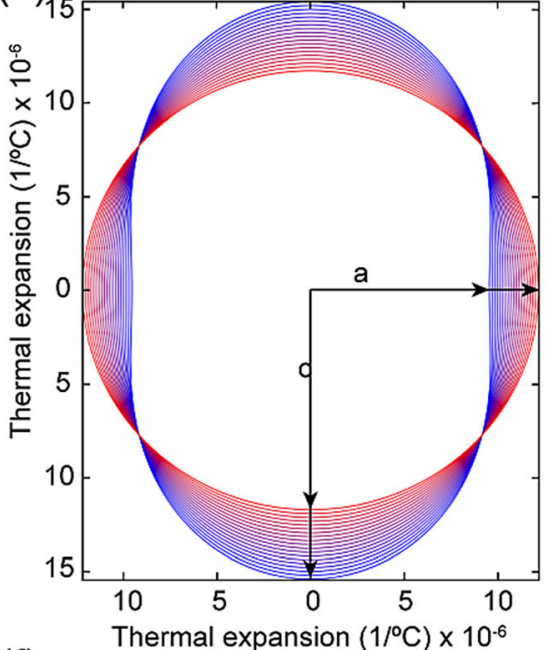

(f)

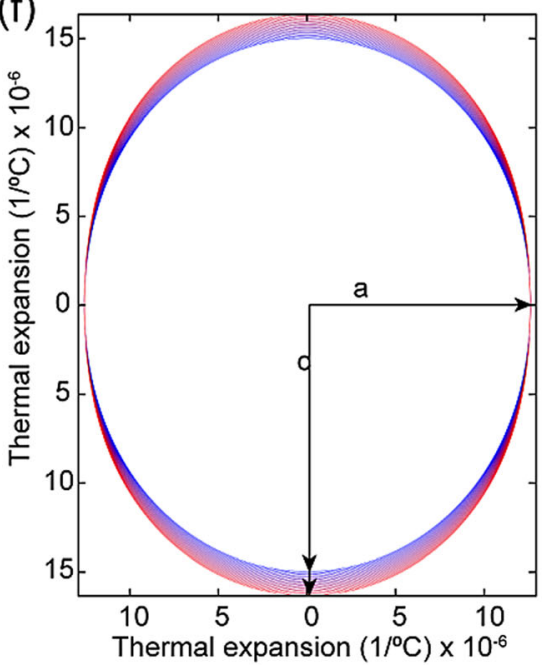

(g) Bi CTE of $\mathrm{Sn} 37 \mathrm{Bi}$ at $\mathrm{T}=40^{\circ} \mathrm{C}$

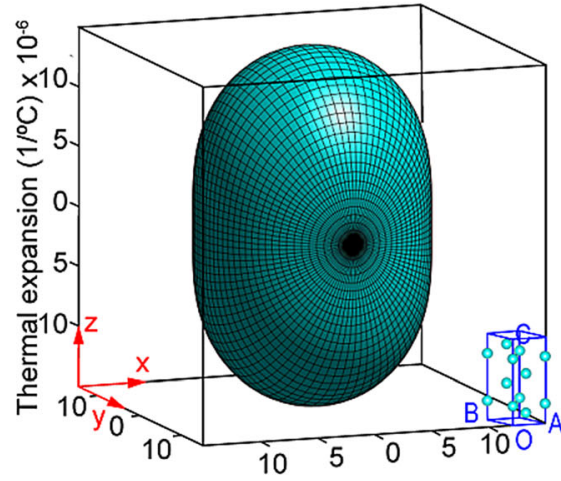

$\mathrm{Bi} \circ$

(h) Bi CTE of Sn37Bi at $\mathrm{T}=120^{\circ} \mathrm{C}$

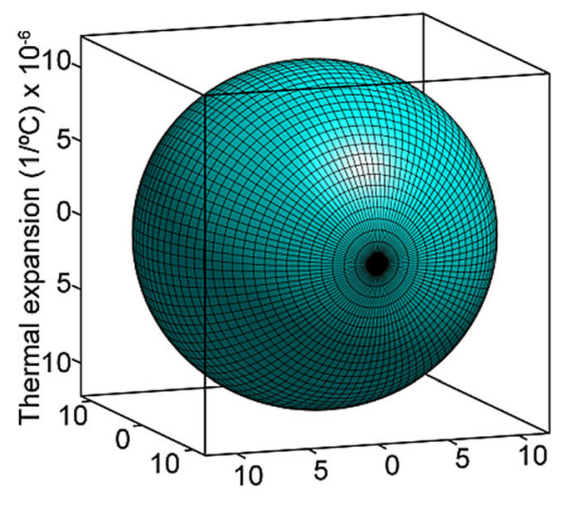

Fig. 8. CTE in the $a, b$, and $c$ directions versus temperature for (a) pure Bi, (b) Sn37Bi alloy, (c) Sn57Bi alloy. Bi CTE cross-sections in the (0;1;0) hkl plane for (d) pure Bi, (e) Sn37Bi alloy, (f) Sn57Bi alloy. Bi CTE ellipsoid of Sn37Bi in the Cartesian coordinate system relative to the trigonal unit cell (blue wireframe) for $(\mathrm{g}) 40^{\circ} \mathrm{C}$ and $(\mathrm{h}) 120^{\circ} \mathrm{C}$ (Color figure online) 
the lattice parameter of $a$ for $\mathrm{Bi}$ phase in $\mathrm{Sn}-\mathrm{Bi}$ is suppressed by the diffusion of $\mathrm{Sn}$ in the Bi phase as the temperature increases before the eutectic point, making the $c / a$ ratio more stable compared with pure Bi.

\section{Directional CTE Determination of Bi}

Figure 8 shows the directional CTE of the $\mathrm{Bi}$ phase for pure $\mathrm{Bi}$, Sn37Bi, and Sn57Bi alloys. The pure $\mathrm{Bi}$ has a larger CTE than the Bi phase in the Sn-Bi alloys, and it increases with temperature in every direction. However, with the addition of Sn, the CTE behavior becomes more complicated. Especially in the Sn37Bi alloy, it can be seen from both the CTE in the $a, b$, and $c$ directions and the CTE cross-sections in Fig. $8 \mathrm{~b}$ and e that the CTE in the $a$ direction increases with temperature but the CTE along the $c$ direction decreases. As the temperature increases, the difference of CTE becomes less, indicating a more isotropic thermal expansion of the Bi phase, which can be clearly seen by comparing the Bi CTE ellipsoid at $40^{\circ} \mathrm{C}$ (Fig. 8g) with that at $120^{\circ} \mathrm{C}$ (Fig. 8h). While the CTE of Bi in Sn57Bi shown in Fig. 8c and findicate that the CTE in the $a$ direction does not change much, the CTE in the $c$ direction increases with temperature. Thus, the addition of the Sn could affect the thermal expansion behavior of the Bi phase in both magnitude and direction, even though the solution of $\mathrm{Sn}$ in $\mathrm{Bi}$ is limited.

\section{CONCLUSION}

The individual $\mathrm{Sn}$ and $\mathrm{Bi}$ phases in $\mathrm{Sn}-57 \mathrm{Bi}$ and Sn-37Bi alloys have been found to have different thermal expansion behaviors compared with pure $\mathrm{Sn}$ or pure $\mathrm{Bi}$, which are dependent on both atomic diffusion in response to solubility limits as well as the direct effect of temperature.

In terms of the $\beta$ Sn phase, the lattice parameters of $\beta \mathrm{Sn}$ in $\mathrm{Sn}-\mathrm{Bi}$ alloys are larger than pure $\beta \mathrm{Sn}$, and show a thermal expansion trend that can be interpreted with respect to the shape of the solvus of the $\mathrm{Sn}-\mathrm{Bi}$ equilibrium phase diagram. It has been shown that, while diffusion and temperature impact the crystal structure together for Sn-Bi alloys, the former has the more significant influence compared to the latter. The results and DFT calculations also indicate that the formation of Bi-rich planes in the $\beta$ Sn crystal structure tends to be parallel to the (001) planes, which results in a larger influence on lattice parameters in the $a$ and $b$ directions than in the $c$ direction. The directional CTE derived from the lattice parameters shows anisotropic expansion for $\beta \mathrm{Sn}$ in $\mathrm{Sn} 57 \mathrm{Bi}$, and the CTE along the $a$ direction becomes larger than that in the $c$ direction as the temperature increases.

For the Bi phase, which exists both as a eutectic phase and as dispersed precipitates within the primary Sn phase, the lattice parameters increase during heating with an inflection near the eutectic temperature, which may be caused by the precipitation of Sn from Bi. Compared with pure $\mathrm{Bi}$, the unit cell is reduced in volume for the $\mathrm{Bi}$ phase in the $\mathrm{Sn}-\mathrm{Bi}$ alloys, and the ratio of the c/a change is smaller than in pure $\mathrm{Bi}$. The diffusion of $\mathrm{Sn}$ in $\mathrm{Bi}$ also influences the CTE of the Bi phase, while, in $\mathrm{Sn} 37 \mathrm{Bi}$, expansion became more isotropic as the temperature increases.

This paper concludes that, in the Sn-Bi system, the diffusion or precipitation of atoms influences the lattice parameters and CTE, which, due to the large changes in solubility with temperature in this system, should not be neglected in service life prediction modeling. This research provides fundamental information for the application of Sn-Bibased low-temperature solders, and should help better understand the morphology and properties of the solder alloys under thermal cycling. In the future, we plan to find the specific concentration of $\mathrm{Bi}$ in the $\beta \mathrm{Sn}$ phase at different temperatures in Sn$\mathrm{Bi}$ alloys to better quantify the relationship between thermal expansion behavior and composition, and are also interested in investigating how additional elements diffused from substrates in a solder joint influence this behavior.

\section{ACKNOWLEDGEMENTS}

We wish to acknowledge the University of Queensland's Research Computing Center (RCC) and the Australian Synchrotron powder diffraction beamline for their support in this research.

\section{FUNDING}

This work was supported by Nihon Superior Co., Ltd., Japan (Grant Number 2016001895 and 2021002341); the Australian Research Council (ARC), Australia (Grant Number DP200101949 and LP180100595); Australian Synchrotron beamtime (Grant Number AS211/PD/16842);The University of Queensland, Australia (Grant Number 2021002690). Open Access funding enabled and organized by CAUL and its Member Institutions.

\section{DECLARATIONS}

\section{CONFLICT OF INTEREST}

The authors declare no conflict of interest.

\section{OPEN ACCESS}

This article is licensed under a Creative Commons Attribution 4.0 International License, which permits use, sharing, adaptation, distribution and reproduction in any medium or format, as long as you give appropriate credit to the original author(s) and the source, provide a link to the Creative Commons licence, and indicate if changes were made. The images or other third party material in this article are included in the article's Creative 
Commons licence, unless indicated otherwise in a credit line to the material. If material is not included in the article's Creative Commons licence and your intended use is not permitted by statutory regulation or exceeds the permitted use, you will need to obtain permission directly from the copyright holder. To view a copy of this licence, visit $h$ ttp://creativecommons.org/licenses/by/4.0/.

\section{SUPPLEMENTARY INFORMATION}

The online version contains supplementary material available at https://doi.org/10.1007/s11837021-05145-4.

\section{REFERENCES}

1. Directive (EU) 2017/2102 of the European Parliament and of the Council of 15 November 2017 amending Directive 2011/ $65 / \mathrm{EU}$ on the restriction of the use of certain hazardous substances in electrical and electronic equipment (Text with EEA relevance. ), https://eur-lex.europa.eu/legal-content/E $\mathrm{N} / \mathrm{TXT} /$ ?uri=CELEX\%3A32017L2102. Accessed 2 November 2021.

2. J. Feng, D.E. Xu, Y. Tian, and M. Mayer, IEEE Trans. Compon., Packag. Manuf. Technol., 9, 1623 (2019). https://d oi.org/10.1109/TCPMT.2019.2901651.

3. H. Kang, S.H. Rajendran, and J.P. Jung, Metals 11, 364. h ttps://doi.org/10.3390/met11020364 (2021).

4. Z. Mei, and J.W. Morris, J. Electron. Mater. 21, 599. http s://doi.org/10.1007/BF02655427 (1992).

5. A. Prakash, K. Byrd, R. Sidhu, S. Elhalawaty, N. Wu, H. Okumura, S. Erukula and J. Lim, Challenges and key learnings in enabling Low Temperature Solder (LTS) technology at packaging components supply base. Paper presented at the 2021 IEEE 71st Electronic Components and Technology Conference (ECTC), San Diego, CA, USA, 1 June-4 July 2021.

6. R. Strauss, and S. Smernos, Circuit World 10, 23. https://doi. org/10.1108/eb043724 (1984).

7. F. Wang, H. Chen, Y. Huang, L. Liu, and Z. Zhang, J. Mater. Sci.: Mater. Electron. 30, 3222. https://doi.org/10.1007/s108 54-019-00701-w (2019).

8. F. Hua, M. Zequn and J. Glazer, Eutectic Sn-Bi as an alternative to $\mathrm{Pb}$-free solders. Paper presented at the 1998 Proceedings. 48th Electronic Components and Technology Conference (Cat. No.98CH36206), Seattle, WA, USA, 25-28 May 1998.

9. A. Dobosz, and T. Gancarz, J. Phys. Chem. Ref. Data 47, 013102. https://doi.org/10.1063/1.5010151 (2018).

10. J.A. Depiver, S. Mallik, and D. Harmanto, Adv. Mater. Process. Technol., 7, 1 (2020). https://doi.org/10.1080/23740 68X.2020.1751514.

11. S. Mokler, R. Aspandiar, K. Byrd, O. Chen, S. Walwadkar, K. Tang, M. Renavikar and S. Sane, The application of Bibased solders for low temperature reflow to reduce cost while improving SMT yields in client computing systems.
Paper presented at the Proceedings of SMTA International, Rosemont, IL, USA, 25-29 September 2016.

12. T.B. Ratanawilai, B. Hunter, G. Subbarayan, and D. Rose, IEEE Trans. Compon. Packag. Technol. 26, 712. https://doi. org/10.1109/TCAPT.2003.821685 (2003).

13. M.-C. Liao, P.-S. Huang, Y.-H. Lin, M.-Y. Tsai, C.-Y. Huang, and T.-C. Huang, Appl. Sci. 7, 739. https://doi.org/10.3390/a pp7070739 (2017).

14. R. Coyle, M. Reid, C. Ryan, R. Popowich, P. Read, D. Fleming, M. Collins, J. Punch, and I. Chatterji, The influence of the $\mathrm{Pb}$-free solder alloy composition and processing parameters on thermal fatigue performance of a ceramic chip resistor. Paper presented at the 2009 59th Electronic Components and Technology Conference, San Diego, CA, USA, 26-29 May 2009.

15. E. Dalton, G. Ren, J. Punch, and M.N. Collins, Mater. Des. 154, 184. https://doi.org/10.1016/j.matdes.2018.05.030 (2018).

16. M. Motalab, Z. Cai, J.C. Suhling, and P. Lall, Determination of Anand constants for SAC solders using stress-strain or creep data. Paper presented at the InterSociety Conference on Thermal and Thermomechanical Phenomena in Electronic Systems 13th, San Diego, CA, USA, 30 May-1 June 2012.

17. G. Chen, X. Zhao, and H. Wu, Adv. Mech. Eng. 9, 1. https://d oi.org/10.1177/1687814017714976 (2017).

18. P. Cucka, and C.S. Barrett, Acta Crystallogr. 15, 865. http s://doi.org/10.1107/S0365110X62002297 (1962).

19. S.A. Belyakov, and C.M. Gourlay, Thermochim. Acta 654, 65. https://doi.org/10.1016/j.tca.2017.05.009 (2017).

20. K. Momma, and F. Izumi, J. Appl. Crystallogr. 44, 1272. h ttps://doi.org/10.1107/S0021889811038970 (2011).

21. B.-J. Lee, C.-S. Oh, and J.-H. Shim, J. Electron. Mater. 25, 983. https://doi.org/10.1007/BF02666734 (1996).

22. F. Wang, Y. Huang, Z. Zhang, and C. Yan, Materials 10(8), 1. https://doi.org/10.3390/ma10080920 (2017).

23. V.T. Deshpande, and D.B. Sirdeshmukh, Acta Crystallogr. 14, 355. https://doi.org/10.1107/S0365110X61001212 (1961).

24. K. Nogita, M.A.A.M. Salleh, S. Smith, Y.Q. Wu, S.D. McDonald, A.G.A. Razak, T. Akaiwa, and T. Nishimura, Effects of $\mathrm{Bi}$ in $\mathrm{Sn}-\mathrm{Cu}$ based lead-free solder alloys and interconnects. Paper presented at the 2017 International Conference on Electronics Packaging (ICEP), Yamagata, Japan, 19-22 April 2017.

25. J.C. Slater, J. Chem. Phys. 41, 3199. https://doi.org/10.1063/ 1.1725697 (1964).

26. R.I. Belousov, and S.K. Filatov, Glass Phys. Chem. 33, 271. h ttps://doi.org/10.1134/S1087659607030157 (2007).

27. Z.A. Jones, P. Sarin, R. Haggerty, and W. Kriven, J. Appl. Crystallogr. 46, 550. https://doi.org/10.1107/S002188981300 2938 (2013).

28. J.W. Xian, G. Zeng, S.A. Belyakov, Q. Gu, K. Nogita, and C.M. Gourlay, Intermetallics 91, 50. https://doi.org/10.1016/ j.intermet.2017.08.002 (2017).

29. P.T. Vianco, and J.A. Rejent, J. Electron. Mater. 28, 1127. h ttps://doi.org/10.1007/s11664-999-0250-4 (1999).

30. J. Vizdal, M.H. Braga, A. Kroupa, K.W. Richter, D. Soares, L.F. Malheiros, and J. Ferreira, CALPHAD: Comput. Coupling Phase Diagrams Thermochem. 31, 438. https://doi.org/ 10.1016/j.calphad.2007.05.002 (2007).

Publisher's Note Springer Nature remains neutral with regard to jurisdictional claims in published maps and institutional affiliations. 